Artigo original

Hegemonia - Revista Eletrônica do Programa de Mestrado em Direitos Humanos, Cidadania e Violência/Ciência Política do Centro Universitário Unieuro

ISSN: $1809-1261$

UNIEURO, Brasília, número 29, Janeiro a Junho de 2020, pp. 177-188.

Recebido em: 27/5/2019

Avaliado em: 8/6/2019

Aprovado em: 28/7/2019

\title{
A TEORIA DAS REPRESENTAÇÕES SOCIAIS: ENSAIO DE APROXIMAÇÃO
}

\author{
Ângelo Roberto Rosa Ávila ${ }^{1}$ e Carlos F. Domínguez Avila ${ }^{2}$
}

Resumo: Este artigo discute as concepções contemporâneas de sociólogos e cientistas, mais especificamente sobre um novo paradigma que vem suscitando e provocando debates nas mais variadas áreas de conhecimento, e diz respeito à Teoria das Representações Sociais (TRS). Dentre outros fatores, corresponde a fenômenos específicos que estão relacionados com um modo de compreender a realidade, e de se comunicar através do senso comum. Nessa linha de raciocínio, a pretensão foi relacionar e descrever aspectos que refletem as várias representações temáticas, neste caso, a sustentabilidade e a educação ambiental, que está fazendo parte do cotidiano das populações de todos os continentes, e se relaciona com as novas formas de representações sociais, à medida que reflete o modo de compreensão dos indivíduos, destacadamente no que se refere às atitudes frente aos recursos naturais renováveis tendo como uma visão global a Sustentabilidade Ambiental. Dentre outros teóricos, foram citados Edgar Morin (2000) e Serge Moscovici (2003), ambos pontuam as representações sociais sob a ótica interdisciplinar, uma vez que propicia investigar o senso comum, considerando o contexto social, cultural e histórico, que é eminentemente um processo de construção das representações societárias.

Palavras - chave: Interdisciplinaridade; Representações Sociais; Sustentabilidade Ambiental.

Abstract: This article discussed about contemporary conceptions of sociologists and scientists, more specifically on a new paradigm that has raised and provoking discussions in various areas of knowledge, and concerns the Theory of Social Representations (TRS). Among other factors corresponding to specific phenomena that are related to a way of understanding reality and to communicate through common sense. In this line of reasoning, the intention was to relate and describe aspects that reflect the various thematic representations in this case, sustainability and environmental education, which is part of the daily lives of people from all continents, and relates to the new forms of social representations, as it reflects the way of understanding of individuals, notably with regard to attitudes towards renewable natural resources as having a global vision of environmental sustainability. Among other authors, were cited Edgar Morin (2000) and Serge Moscovici (2003), both punctuate the social representations under the interdisciplinary perspective, since it provides investigate common sense, considering the social, cultural and historical, that is eminently one process of building the corporate representations.

Keywords: Interdisciplinarity; Social Representations; Environmental Sustainability.

\footnotetext{
${ }^{1}$ Mestre em Ciência Política e Professor Titular da Secretaria de Estado de Educação do Distrito Federal.

${ }^{2}$ Doutor em História e docente do Centro Universitário Unieuro.
} 
Artigo original

Hegemonia - Revista Eletrônica do Programa de Mestrado em Direitos Humanos, Cidadania e Violência/Ciência Política do Centro Universitário Unieuro

ISSN: $1809-1261$

UNIEURO, Brasília, número 29, Janeiro a Junho de 2020, pp. 177-188.

\section{INTRODUÇÃO}

O mundo contemporâneo configurado como moderno de acordo com as concepções de sociólogos e cientistas, fez surgir paradigmas e teorias, dentre as quais, a Teoria das Representações Sociais $\left(\right.$ TRS) ${ }^{3}$, que de acordo com Moscovici (2007) são fenômenos específicos que estão relacionados com um modo de compreender a realidade, e de se comunicar através do senso comum.

Portanto, corresponde a um processo de duas vias, o individual e o coletivo, sendo que a primeira perspectiva diz respeito a um fenômeno perceptivo onde predominam as subjetividades ${ }^{4}$ e a segunda perspectiva corresponde às experiências cotidianas dos indivíduos.

Nessa linha de raciocínio a pretensão deste artigo científico é refletir sobre uma temática contemporânea e emergente que diz respeito ao paradigma da sustentabilidade ${ }^{5}$ ambiental, que está fazendo parte do cotidiano das populações de todos os continentes, e se relaciona com as novas formas de representações sociais, à medida que reflete o modo de compreensão dos indivíduos, destacadamente no que se refere às atitudes frente aos recursos naturais como água, parques, rios, fauna, e todos os elementos ambientais que favorecem a qualidade de vida.

A sustentabilidade ambiental, também denominada como ecodesenvolvimento, tem sido debatida no meio acadêmico como uma dimensão de sobrevivência humana multidimensional, portanto, exige uma compreensão efetiva sobre preservação, reuso, reciclagem, conscientização, atitude política, prevenção, ou seja, tudo que pode "insinuar como uma resposta aos problemas emergentes da vida cotidiana" (ALMEIDA, 2009).

Numa visão globalizada, pode-se observar que o mundo está se voltando para uma questão social coletiva, ou seja, as questões do individualismo estão em queda, e, por outro lado,

\footnotetext{
${ }^{3}$ A TRS - Teoria das Representações Sociais vem se constituindo como um campo de investigação científica que estabelece interface com as Ciências Políticas, e tem como precursores Serge Moscovici e Denise Jodelet.

${ }^{4}$ De acordo com a Psicologia Social se refere a um espaço íntimo do indivíduo (mundo interno) onde se instala a sua opinião, e onde se compõe as emoções, sentimentos e pensamentos.

${ }^{5}$ Consciência e compromisso dos indivíduos em assegurar que os componentes do ecossistema continuem viáveis, de modo a permitir que a capacidade natural do meio ambiente se mantenha em condições equilibradas considerando os recursos naturais renováveis e a biodiversidade.
} 
Artigo original

Hegemonia - Revista Eletrônica do Programa de Mestrado em Direitos Humanos, Cidadania e Violência/Ciência Política do Centro Universitário Unieuro

ISSN: $1809-1261$

UNIEURO, Brasília, número 29, Janeiro a Junho de 2020, pp. 177-188.

as relações sociais cada vez mais procuram visualizar a busca de conhecimentos que se interagem, para melhor solucionar os problemas do cotidiano e da vida social e coletiva.

Convém observar que buscar soluções imediatas não é mais uma questão de ideologia ambiental, mas sim de sobrevivência para as gerações futuras. Essa responsabilidade é todos os sujeitos sociais, não está restrita à comunidade científica, ou ainda, aos intelectuais que explicam a dinâmica da convivência humana com os recursos naturais.

Moscovici (2003) considera os conhecimentos científicos como um suporte para discutir as teorias estabelecidas, de modo a torná-las mais compreensíveis pela comunidade intelectual e acadêmica, alcançando as demais comunidades que incluem todo tipo de indivíduo.

Nesse sentido, o conhecimento passa a ser um sistema de valores e práticas, que tem dupla função: no primeiro momento estabelece uma ordem que possibilita as pessoas a orientar-se em termos teóricos e materiais, no segundo momento, permite que a comunicação seja possível entre os membros comunitários, de modo a facilitar a compreensão e classificação de todos os aspectos que se referem ao mundo vivenciado.

Reigota (2004), por sua vez, ao defender o caráter representativo do meio ambiental, no contexto social, afirma não existir um consenso a respeito, mas, ao mesmo tempo é indiscutível que o meio ambiente é um lugar determinado e percebido, onde os elementos naturais e sociais se relacionam de forma dinâmica, que implicam em processos de criação cultural, como também, transformação do meio natural, que deve ser entendido como uma visão socioambiental.

\section{ABORDAGEM INTERDISCIPLINAR DAS REPRESENTAÇÕES SOCIAIS}

A interdisciplinaridade nasceu como oposição a todo conhecimento que privilegiava conceitos tradicionais, e em seu lugar passa a ser dialogada as questões da cotidianidade. A proposição desse paradigma partiu da ideia de que é importante a interação dos vários níveis de aprendizagem, quais sejam, multi, pluri, inter e transdisciplinar. Desta forma, a interdisciplinaridade torna-se responsável pelo movimento de redimensionamento teórico das ciências e pela revisão dos hábitos de pesquisa, constituindo-se como um novo viés que propugnaria novos caminhos para a educação (FAZENDA, 2008). 
Artigo original

Hegemonia - Revista Eletrônica do Programa de Mestrado em Direitos Humanos, Cidadania e Violência/Ciência Política do Centro Universitário Unieuro

ISSN: $1809-1261$

UNIEURO, Brasília, número 29, Janeiro a Junho de 2020, pp. 177-188.

A proposta interdisciplinar vem quebrar um paradigma da fragmentação dos conteúdos, onde o comportamento científico estaria voltado para uma mudança epistemológica e teórica, e que repercute nas relações das áreas de conhecimento, e seus respectivos conteúdos científicos, com abordagens que desencadeou um novo direcionamento em relação à compreensão da realidade, onde se insere o caráter das representações.

Portanto, pode-se dizer que o paradigma das representações sociais passa por vários fatores, e a cada ano tem se ampliado a discussão, o embate e o debate, a ponto de teóricos como Edgar Morin (2000) afirmar que as representações sociais se "configuram como uma proposta interdisciplinar", uma vez que propicia investigar o senso comum, considerando o contexto social, cultural e histórico, que é eminentemente um processo de construção representativa e significativa.

Nesse sentido, se torna inquestionável o parâmetro interdisciplinar do debate, posto que envolve setores discursivos e fenomenológicos, como saúde, história, sociologia, geografia, política, comunicação e meio ambiente. Este último aspecto (foco do artigo) requer a mobilização e participação social, haja vista que a questão ecológica é parâmetro das práticas sociais, por conseguinte, implica em atitude.

Embora no Brasil somente a partir dos anos 1990 a temática ecológica tenha suscitado vários debates acadêmicos, atualmente tem sido foco de preocupação, discussão, mobilização, e estudos acadêmicos com o intuito de encontrar alternativas capazes de minimizar os impactos provocados pela poluição, pelo desmatamento, e outros descasos relativos à natureza, que sempre provocaram desequilíbrio em função da falta de respeito aos recursos naturais.

Convém salientar que discutir meio ambiente, conforme Ribeiro (2001) é antes de tudo, propor resolutividade e mudar a postura incorreta, ou seja, fomentar a sustentabilidade sob um prisma avançado de desenvolvimento social, associado à justiça socioambiental, de caráter participativo e consciente, e capaz de modificar a postura ética dos indivíduos, portanto, relacionase com um redimensionamento nas (e das) representações sociais.

Nessa perspectiva, convém ressaltar o estudioso Santos (2005), para quem as teorias que envolvem interdisciplinaridade e representações sociais correspondem a um conjunto de conceitos articulados:

[...] que têm origem nas práticas sociais e diversidades grupais cujas funções é dar sentido à realidade social, produzir identidades, organizar as 
Artigo original

Hegemonia - Revista Eletrônica do Programa de Mestrado em Direitos Humanos, Cidadania e Violência/Ciência Política do Centro Universitário Unieuro

ISSN: $1809-1261$

UNIEURO, Brasília, número 29, Janeiro a Junho de 2020, pp. 177-188.

comunicações e orientar as condutas. Não é, portanto, todo e qualquer conhecimento do senso comum que pode ser polimorfo, isto é, passível de assumir formas diferentes para cada contexto social, e, ao mesmo tempo, ter relevância cultural para o grupo.

Portanto, a partir da percepção do pesquisador Santos (2005), as teorias do senso comum podem ser caracterizadas como representações sociais, o que equivale dizer que refletem as realidades do contexto social, reforçando a identidade grupal, organizando as comunicações e norteando as condutas dos indivíduos.

Dessa forma, as representações sociais condizem com a construção societária, sem perder de vista os sujeitos, que são atores sociais atuantes em todos os processos coletivos. Por conta dessa análise, Moscovici (2003) afirmara que a sociedade é produto humano, ou seja, o homem é um produto social, que ao se apropriar da realidade, reconstrói e reelabora.

Nessa linha de raciocínio, se a representação social não é meramente reproduzir conceitos, mas reconstruir as informações, a sustentabilidade ambiental é um viés de discussão que tem passado por processos determinantes no que diz respeito ao modo de conviver e respeitar a natureza (fauna e flora), os recursos necessários à sobrevivência humana - água, plantas, vegetais, minérios, rios - dentre outros.

Por esta razão, não se pode ignorar o conhecimento do senso comum, que embora vivenciado fora dos muros da academia, segue uma lógica diversificada, interdisciplinar, cognitiva ${ }^{6}$ e social, sem, ao mesmo tempo, desconsiderar o viés científico e acadêmico. Em outras palavras, a teoria da representação social tem como ponto de partida o rompimento com o pensamento tradicional, por conseguinte a valorização da consciência coletiva, uma vez que ela é fruto de pesquisas na área psicossocial.

Por conta dessa contextualização, convém salientar que embora a origem da teoria das representações sociais (TRS) esteja atrelada ao caráter psicológico e social (sujeito, objeto e sociedade), a intenção de Moscovici (2003) ao se aprofundar na sua dimensão interdisciplinar foi superar o viés fragmentado do conhecimento. Essa linha de pensamento é que coloca a propositura

\footnotetext{
6 Processo de aquisição do conhecimento que envolve percepção, atenção, associação, memória, raciocínio, imaginação, pensamento e linguagens.
} 
Artigo original

Hegemonia - Revista Eletrônica do Programa de Mestrado em Direitos Humanos, Cidadania e Violência/Ciência Política do Centro Universitário Unieuro

ISSN: $1809-1261$

UNIEURO, Brasília, número 29, Janeiro a Junho de 2020, pp. 177-188.

da interdisciplinaridade, posto que atualmente busca-se um entendimento diversificado do contexto social, uma nova leitura e releitura de mundo.

Ou seja, a teoria das representações sociais se apresenta, dentre outras formas fenomenológicas, como uma maneira de interpretar e pensar a realidade cotidiana, "uma forma de conhecimento desenvolvida pelos indivíduos e pelos grupos sociais" (com suas características culturais), para fixar suas posições em relação a situações, eventos, fatos, mudanças e etc. (SÊGA, 2015).

A representação social é sempre a atribuição da posição que as pessoas ocupam na sociedade, haja vista que ela se apresenta, quando representa alguma coisa ou alguém. Nesse sentido, ela não é cópia do real, nem é o ideal, mas sim, um processo (ou vários) pelo qual se estabelece a relação entre o mundo e as coisas.

Além disso, a representação social tem dentre outras características:

- A propriedade de intercambiar a percepção e o conceito;

- Um caráter simbólico ${ }^{7}$ e significante ${ }^{8}$;

- Um caráter autônomo e criativo.

Por esta razão a perspectiva epistemológica ${ }^{9}$ defendida por Morin (2000) para quem a representação é aquilo que se pode apreender pelos sentidos, pela imaginação, de modo a superar a clivagem ${ }^{10}$ entre ciência e senso comum, tratando-as "como construções sociais sujeitas às determinações sócio históricas".

Nessa linha de raciocínio, a representatividade se refere a algo inquietante e que faz suscitar diálogos sobre tudo que a sociedade vivencia, posto que não é somente o debate sobre a ciência, ao contrário, provoca questionamentos sobre a relação indivíduo-sociedade, de acordo com a complexidade e com a realidade, que certamente não escapa do parâmetro trans, multi e interdisciplinar.

Como diria Morin (2000) o que interessa é privilegiar pensamentos que sejam capazes de quebrar fronteiras entre as disciplinas, uma vez que a educação abrange tudo que é inerente à

\footnotetext{
${ }^{7}$ Elemento representativo que está em lugar de algo, figuras, imagens, gestos, por exemplo.

${ }^{8}$ Elemento material e fonético do signo.

${ }^{9}$ Reflexão sobre etapas do conhecimento humano e sua relação com a evolução da sociedade.

${ }^{10}$ Relaciona-se ao ato de dividir e separar.
} 
Artigo original

Hegemonia - Revista Eletrônica do Programa de Mestrado em Direitos Humanos, Cidadania e Violência/Ciência Política do Centro Universitário Unieuro

ISSN: $1809-1261$

UNIEURO, Brasília, número 29, Janeiro a Junho de 2020, pp. 177-188.

sociedade, afinal, "tudo que é humano é ao mesmo tempo psíquico, sociológico, econômico, histórico, demográfico", portanto, o que interessa é explorar a complexidade da realidade que se vivencia, com todos os viés e dimensões.

Por isso, não basta apenas, colocar a questão interdisciplinar como uma proposta isolada de alguns cientistas, mas de maneira que venha buscar através de uma educação consciente, disciplinada e ao mesmo tempo, reformuladora, onde se volte as ideias inerentes às áreas do conhecimento como um "todo", ou seja, estimular as formas de pensamento tirando de cada movimento idealista uma ação simples, mas com a capacidade de envolver toda uma sociedade pelo bem comum.

O contato e o diálogo com a natureza têm início com o surgimento da humanidade, que por sua vez, implica em representação social. Essas representações começam a ser pesquisadas pela filosofia e pela sociologia até adquirir um viés psicossocial, portanto, de caráter metafísico e interdisciplinar, onde há uma defesa de que não se pode reduzir a natureza às esferas científicas, uma vez que são muitas informações, segredos e mistérios, que vão além dos elementos laboratoriais e acadêmicos.

Pesquisadores como Reigota (2004) coloca que a partir do século XVIII começaram as manifestações do "amor" pela natureza, como também a defesa da existência das criaturas selvagens, momento este que ele denomina como um conflito crescente entre as novas sensibilidades e os fundamentos materiais da sociedade ocidental.

Este período, na opinião de Reigota (2004) já suscita o viés das novas representações sociais, uma vez que surgem os novos comportamentos da civilização moderna, que por um lado defende a conservação da natureza, e por outro, sua transformação em ferramentas úteis, como por exemplo, petróleo, pneus, plásticos e etc.

Portanto, as novas representações sociais que implicam em desenvolvimento e problemas ambientais, como por exemplo, degradação e esgotamento de fontes naturais renováveis. Em outras palavras, ocorre o surgimento de uma nova ética social, que envolve um sistema de valores, uma busca de harmonização entre o homem e a natureza.

Todos esses aspectos implicam em conscientizar a vida como um valor intrínseco, como uma auto realização, como algo mais importante que o desenvolvimento econômico e o 
Artigo original

Hegemonia - Revista Eletrônica do Programa de Mestrado em Direitos Humanos, Cidadania e Violência/Ciência Política do Centro Universitário Unieuro

ISSN: $1809-1261$

UNIEURO, Brasília, número 29, Janeiro a Junho de 2020, pp. 177-188.

consumismo. Essa representação requer que haja uma adequação da tecnologia com o meio ambiente, uma nova forma de organização comunitária.

Para Reigota (2004), essa abordagem é sistêmica e segue ideários do mesmo modo que o movimento feminista, o movimento negro, o movimento homossexual, dentre outros que exigem um processo de comunicação interpessoal e intergrupal capazes de encontrar explicações face a um contexto global.

Nessa linha de raciocínio, a globalidade e todas as suas esferas de concepção de mundo (avanços tecnológicos, inovações nos transportes e meios de comunicação) também modificou as relações de espaço e de tempo, ou seja, as distâncias espaço-temporal, e os estilos de vida, uma espécie de ecologia subjetiva, que é antes de tudo, saber o que significa tráfego de carros e saúde, saber a diferença entre amor e compaixão, além de todas as modificações utilitárias, como solidariedade e comunidade.

Todos esses fatores condizem com uma responsabilidade social emergente, cuja percepção ecológica vai desde o contato e o cuidado com a natureza, sua preservação e destruição, sua integração, seu caráter exótico e utilitário, tais como, limpeza, lixo, poluição, preservação, verde, vida, animais, qualidade de vida, ecossistema, dentre outros.

Pode-se dizer que as representações sociais contemporâneas passam por uma nova percepção de realidade, que inclui comunidades educativas, ecológicas, políticas, raciais, culturais, comerciais e etc. Diante de todos esses preceitos o que importa é a busca pelo equilíbrio ecológico e a conquista de uma nova vida cotidiana.

Evidentemente que esses pressupostos condizem com a emergência conceptual de consciência ecológica, com novas práticas de cidadania em que a rede de inter-relação, composta por indivíduo-sociedade-natureza, seja efetivamente valorizada, haja vista que as representações sociais têm (ou pelo menos deveriam ter) processos formativos que de fato suscitem novas atitudes e novos comportamentos.

Deste modo, representações sociais correspondem também a um conjunto de princípios construídos de modo interativo e compartilhado, em que diferentes grupos possam compreender o ideário e o objetivo de uma nova visão societária, e, concorrentemente, modificar para melhor, todo o coletivo, seja local, regional, nacional, global e planetário. 
Artigo original

Hegemonia - Revista Eletrônica do Programa de Mestrado em Direitos Humanos, Cidadania e Violência/Ciência Política do Centro Universitário Unieuro

ISSN: $1809-1261$

UNIEURO, Brasília, número 29, Janeiro a Junho de 2020, pp. 177-188.

\section{CONTRIBUIÇÕES DA TEORIA DAS REPRESENTAÇÕES SOCIAIS NO CONTEXTO EDUCATIVO}

Diante do debate colocado até este momento se evidencia que a Teoria das Representações Sociais (TRS) também tem sido valorizada pelo campo da educação, que implica em compreender procedimentos metodológicos e propostas educativas capazes de mudar a realidade, concorrentemente, formar cidadãos críticos e participativos, sem privilegiar somente o desempenho quantitativo dos estudantes, ao contrário, fazê-los partícipes dos episódios, nas mais diferenciadas temáticas.

Em outras palavras, a construção dos saberes (senso comum ou ciência) não escapa da representatividade social dos sujeitos envolvidos no processo, que passa por conceitos, métodos, reflexões, discursos, interações, atitudes, dentre outros aspectos capazes de redimensionar a concepção dos sujeitos.

Por conta desses fatores, Ferreira (2004) pontua que as representações (sociais) no que diz respeito ao meio ambiente (educação ambiental) são situadas no âmbito das concepções científicas e históricas, haja vista que a relação “dos seres humanos com o meio ambiente" superou a visão utilitarista dos recursos naturais, e em seu lugar prevalece a perspectiva de uma abordagem associada a fatores políticos, culturais, sociais e econômicos, ou seja, uma percepção holística e plural, que leva em conta a dignidade da pessoa humana, a qualidade do ensino, e ainda, a qualidade de vida da população.

Portanto, o processo de ensino e aprendizagem é também uma área onde as representações sociais são vistas como construções coletivas, multifacetada e interdisciplinar, que além de pertinentes são constituídas por elementos cognitivos, afetivos, reflexivos, simbólicos, culturais, políticos, dentre outros que são gerados pelos sujeitos sociais à medida que interagem com a realidade na qual estão inseridos.

Equivale dizer que a aprendizagem no atual contexto requer uma nova forma de olhar os espaços formativos, cujo conteúdo deve representar socialmente a realidade e sua complexidade, denunciar os desmandos, a injustiça social e contribuir com o bem-estar, com o respeito às diferenças. Afinal, a escola é uma comunidade de significados, cujo conjunto de conceitos, 
Artigo original

Hegemonia - Revista Eletrônica do Programa de Mestrado em Direitos Humanos, Cidadania e Violência/Ciência Política do Centro Universitário Unieuro

ISSN: $1809-1261$

UNIEURO, Brasília, número 29, Janeiro a Junho de 2020, pp. 177-188.

proposições, diretrizes, debates e explicações têm relação direta com o cotidiano, o modo de vida e as tradições das comunidades.

Nesse bojo, se faz presente o meio ambiente e todos os seus elementos representativos em termos de equilíbrio, sobrevivência, qualidade de vida, cidadania, dignidade, direitos humanos, participação, autonomia, consciência coletiva, atitudes e comportamentos respeitosos e adequados.

São esses fatores que enriquecem as experiências grupais das representações humanas e sociais, e que certamente a educação tem um papel preponderante e inestimável. Como afirma Arruda (2005), as pesquisas que têm procurado propagar e valorizar as representações sociais, seja na área das ciências sociais, das ciências políticas ou educação, tem revelado preocupação em apresentar a mudança de paradigmas no sistema educacional.

Essa afirmativa permite dizer que dentre outros paradigmas pertinentes nesse contexto, a interdisciplinaridade propicia se aprofundar em todos os elementos que até então foram descritos e que refletem o valor de conhecer e aprender sobre tudo aquilo que é social e humano (educação, meio ambiente, respeito mútuo, bem-estar e etc.).

\section{CONSIDERAÇÃOS FINAIS}

Este artigo discutiu sobre concepções contemporâneas de sociólogos e cientistas, mais especificamente sobre um novo paradigma que vem suscitando e provocando discussões nas mais variadas áreas de conhecimento, e diz respeito à Teoria das Representações Sociais (TRS), que dentre outros fatores epistemológicos, valoriza fenômenos específicos que estão relacionados com um modo de compreender a realidade, e de se comunicar através do senso comum.

Nessa linha de raciocínio, a pretensão deste artigo científico foi relacionar e descrever aspectos que refletem as várias representações temáticas, neste caso, a sustentabilidade ambiental, que está fazendo parte do cotidiano das populações de todos os continentes, e se relaciona com as novas formas de representações sociais, à medida que reflete o modo de compreensão dos indivíduos, destacadamente no que se refere às atitudes frente aos recursos naturais renováveis. 
Artigo original

Hegemonia - Revista Eletrônica do Programa de Mestrado em Direitos Humanos, Cidadania e Violência/Ciência Política do Centro Universitário Unieuro

ISSN: $1809-1261$

UNIEURO, Brasília, número 29, Janeiro a Junho de 2020, pp. 177-188.

Dentre outros destaques foi colocada a definição da Teoria das Representações Sociais, que se configura como uma proposta interdisciplinar, uma vez que propicia investigar o senso comum, considerando o contexto social, cultural e histórico, que é eminentemente um processo de construção das representações societárias.

Nesse sentido, ficou evidente o parâmetro interdisciplinar do debate, posto que envolva setores discursivos e fenomenológicos, como saúde, história, sociologia, geografia, política, comunicação e meio ambiente. Este último aspecto (foco do artigo) requer a mobilização e participação social, haja vista que a questão ecológica é parâmetro das práticas sociais, por conseguinte, implica em atitude.

Além disso, discutir meio ambiente é antes de tudo, propor resolutividade e mudar a postura incorreta, ou seja, fomentar a sustentabilidade sob um prisma avançado de desenvolvimento social, associado à justiça socioambiental, de caráter participativo e consciente, e capaz de modificar a postura ética dos indivíduos, portanto, redimensionar as representações sociais.

Dessa forma, se pode afirmar que as representações sociais condizem com a construção societária, sem perder de vista os sujeitos, que são atores sociais atuantes em todos os processos coletivos, posto que se a representação social não é meramente reproduzir conceitos, mas reconstruir as informações, a sustentabilidade ambiental é um viés de discussão que tem passado por processos determinantes no que diz respeito ao modo de conviver e respeitar a natureza (fauna e flora), os recursos necessários à sobrevivência humana - água, plantas, vegetais, minérios, rios - dentre outros.

Hoje no Congresso Nacional encontramos um comitê de representação da sustentabilidade e cidadania, onde as representações sociais se tornam cada vez mais presentes dentro de uma sociedade solidária com a construção de idéias e pensamentos voltados para a capacidade de se manter em equilíbrio constante com o meio em que vive.

Dessa forma, podemos considerar que "não se pode mais" estar desconectado, desalinhado e desenformado das ações atuantes desse comitê, que não só coloca a par das situações e realidades do meio ambiente sustentável, como também da capacidade de se proporcionar um desenvolvimento sustentável para a manutenção e organização de uma comunidade mais estável. 
Artigo original

Hegemonia - Revista Eletrônica do Programa de Mestrado em Direitos Humanos, Cidadania e Violência/Ciência Política do Centro Universitário Unieuro

ISSN: 1809-1261

UNIEURO, Brasília, número 29, Janeiro a Junho de 2020, pp. 177-188.

REFERENNCIAS

ALMEIDA, A. M. Abordagem Societal das Representações Sociais. Disponível em: www.scielo.br/pdf/se. Acesso em 27 de maio de 2015.

ARRUDA, A. Pesquisa em Representações Sociais. SP: Casa do Psicólogo, 2005.

COELHO JÚNIOR, N. Dimensões das subjetividades. SP: Fapesp, 2012.

FAZENDA, I. C. A. Didática e Interdisciplinaridade. 13ª edição: SP: Ed Papirus, 2008.

FERREIRA, A. R. Meio ambiente: Representações e práticas dos professores de ciência e biologia. Ponta Grossa: UEPG, 2004.

MORIN, E. O problema epistemológico da complexidade. SP: Ática, 2000.

MOSCOVICI, Serge. Representações sociais: Investigações em psicologia social. Petrópolis: Vozes, 2003.

REIGOTA, Marcos. Meio ambiente e representação social. SP: Cortez, 2004.

RIBEIRO, G. L. Ambientalismo e desenvolvimento sustentável. Revista de Antropologia. SP: USP, n ${ }^{\circ} 34,2001$.

SANTOS, M. C. G. As Representações Sociais de gênero das professoras. Recife: Dissertação de Mestrado pela Universidade Federal de Pernambuco, 2005.

SÊGA, R. A. O conceito de representação nas obras de Denise Jordelet e Serge Moscovici. Porto Alegre: Revista das Ciências Sociais, no 3, julho de 2015. 